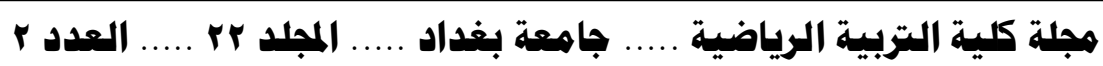

\title{
استخدام زعانف الرجلين الاحادية وكنفف السباحة واثرهما في تطوير انجاز.0 م سباحة فراشة
}

م.د. هصطفى صلاح الدين عزيز

كلية التزبية الرياضية - جامعة بغداد

$p r \cdot q$

$\rightarrow 1 \leqslant r$

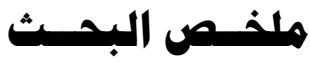

تضمن البحث خمسة ابواب :

اذ احتوى الباب الاول على المقدمة واهمية ومشكلة البحث المتضمنة قلة او ضعف في

استخدام زعانف الرجلين الاحادية وكفوف السباحة من قبل المدربين في تطوير انجاز سباحة الفراشة ، وقد هدفت الدراسة الى معرفة اثر استخدام زعنفة الرجلين الاحادية وكفوف السباحة في تطوير انجاز · مم فراشة ، ومعرفة اي الوسيلتين المستخدمتين افضل في تطوير انجاز الفعالية المذكو ، واعتمــ البـاحث المنهج التجريبي بطريقة المقـارنة لتحقـيق فروض البــث في ان هناك اثر لاستخدام زعنفة الرجلين الاحادية والكفوف في تطوير انجاز ، هم فراشة ، وان هناك فروق معنوية ذات دلالة احصائية في نتائج استخدام الوسيلتين التريبيتين في تطوير هذه الفعالية

اما الباب الثاني فقد تضمن بعض الدراسات النظرية التي تناولت القوانين والمقاومات

الخاصة في السباحة سباحة الفراشة ، وشرح تفصيلي لتكنيك سباحة الفراشة . 


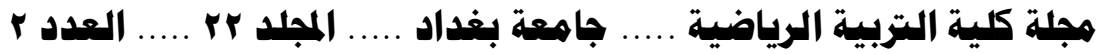

في حين تضمن الباب الثالث منهجية البحث معتمدا المنهج التجريبي بطريقة المقارنة لملائمته مشكلة البحث واجراءاته الميدانية في اختيار الباحث 12 سباح من سباحي الاتحاد العراقي للسباحة (اندية بغداد) اذ تعدد اختيارهم من الفئة العمرية (13 ـ 14) سنة ومن سباحي فعالية 50م فراشة متقاربين في العمر الزمني والقياسات الجسمية اذ تراوحت اوزانهم بين (54 59)كفم في حين تراوحت اطوالهم بين (1.62 ـ1.65)متر وكذلك من ذوي مستوى انجاز متقارب في الفعالية المذكورة تم التوصل بعد اجراء اختبار سباحة ـم فراشة للسباحين المنتخبين ضمن العينة والذي اعتبر الاختبار القبلي للبحث ، ويهذا فقد كانت العينة متجانسة من حيث العمر والطول والوزن ، ويعد التأكد من تجانس وتكافؤ العينة تم تقسيمها عشوائية الى ثلاثة مجاميع متساوية (مجموعتين تجريبية واخرى ضابطة ) حيث ضمت كل مجموعة 4 سباحين وكما يلي :

ـ المجموعة التجريبية الاولى (مجموعة زعنفة الرجلين الاحادية ) 4 سباحين . ـ المجموعة التجريبية الثانية (مجموعة كفوف السباحة ) 4 سباحين . ـ المجموعة الضابطة ( التي لم تستخدم الوسيلتين اعلاه ) 4 سباحين . تضمن الباب الرابع عرض وتحليل نتائج القياسات القبلية والبعدية لاختبار 50م فراثة بعد معالجتها احصائيا بأستخدام الاختبارات الاحصائية ( L.S.D, F,T) حيث بينت النتائج افضلية استخدام الوسيلة التدريبية (زعانف الرجلين الاحادية ) ) ، وعلى اساس ذلك فقد استتجج الباحث في الباب الخامس عدة استتناجات اهمها : < ظهور فروق معنوية د دالة احصائيا" في قيم الانجاز البعدي لسباحة 50م فراشة بين

\section{افراد العينة}

ه ظهور اكبر فرق في قيم الانجاز البعدي لسباحة 50م فراثة بين المجموعة الاولى التي استخدمت الزعانف الاحادية في تدريباتها والمجموعة الثالثة الضابطة التي لم تستخدم

$$
\text { الزعانف او كفوف السباحة في التدريب . }
$$

\& ظهر الفرق معنويا" ايضا" بين المجموعة التجريبية الاولى التي استخدمت الزعانف الاحادية والمجموعة التجريبية الثانية التي استخدت كفوف السباحة في التريب ، كما 


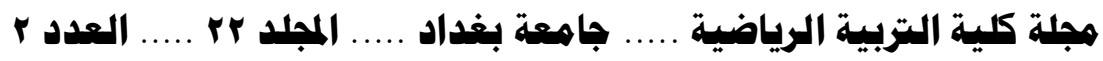

ان استخدام زعانف الرجلين الاحادية في التدريب ذات تأثير اكبر في تطوير انجاز سباحة

الفراشة من استخدام كفوف السباحة في تدريب الاعمار (13 ـ 14) سنة .

وعلى اساس ذلك وصى الباحث بـ :

> خرورة تركيز المدربين على استخدام الوسائل التدريبية المساعدة ولاسيما زعانف الرجلين

$$
\text { الاحادية خلال التدريب المائي لسباحي الفراشة . }
$$

ه اجراء بحوث ودراسات اخرى لاستخدام الزعانف المنفردة والاحادية في تطوير انجاز انواع

اخرى من السباحة (الحرة والصدر والظهر) للمسافات القصيرة ولفئات عمرية مختلف .

Using Leg Fins and Swimming Gloves and Their Effect on

Developing 50m Butterfly Achievement

\author{
Instructor Dr. Mustafa Selah Al Deen Azziz \\ University of Baghdad/College of Physical Education
}

The problem of the research lied in the lack of leg swimming fins and swimming glove use for developing butterfly achievement. The aim of the study is to identify the effect of using swimming fins and swimming gloves on the development of $50 \mathrm{~m}$ butterfly achievement. In addition to that he aimed at identifying the best means used for developing $50 \mathrm{~m}$ butterfly achievement. The researcher hypothesized the existence of positive effects after using swimming fins and gloves on the development of $50 \mathrm{~m}$ butterfly achievement. He also hypothesized significant statistical differences in the results after using these means on the development of this stroke. The researcher used the experimental method to achieve the hypothesis of the research.

The subjects were (12) swimmers of the Iraqi National Swimming Federation of the ages $(13-14)$ years old who swim $50 \mathrm{~m}$ butterfly. The subjects were homogeneous in weight $(54-59)$, height $(1.65-1.62)$ and level of achievement. A $50 \mathrm{~m}$ butterfly test was conducted and was considered the pretest. The subjects were divided into three equal groups; two experimental groups and one controlling group). The first group used swimming fins, the second group used the swimming gloves while the controlling group didn't use 


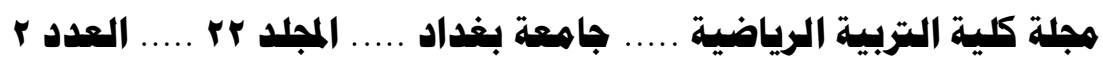

any means. The data was collected and treated statistically using $t$ - tests, $f$ tests and LSD test).

The researcher concluded the following:

- There are significant statistical differences in posttests achievement values in $50 \mathrm{~m}$ butterfly swimming.

- The greatest significant difference was found in posttests achievement values in 50m butterfly swimming in the fist group using swimming fins followed by the controlling group that did not use any of these means.

- There are significant statistically differences between the first group and the second group in favor of the first group that used swimming fins for training young swimmers of the ages ( 13 - 14 years old)

Finally the researcher recommended the following:

- The coaches should pay attention to assisting means especially swimming fins during water training for butterfly stroke.

Making similar researches using swimming fins on the achievement development of other types of short distance races and young age groups.
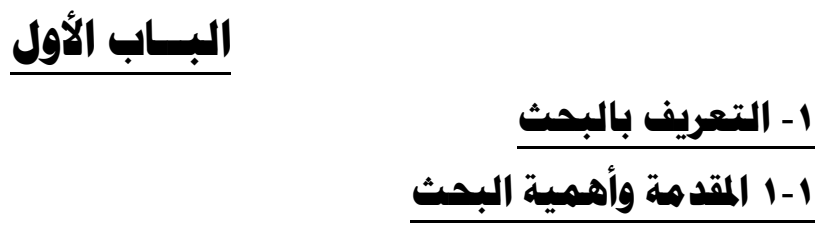

ان ملاحظة التطور العلمي والتكنولوجي في مجالات حياة الانسان لاتقتصر في الجوانب

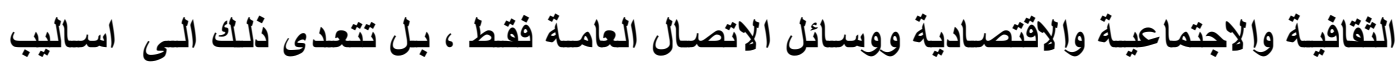
وانشطة الفرد اليومية والطرق المتبعة لممارسة تلك الانشطة ، فلكي يقوم المهندس بتصميم بناء

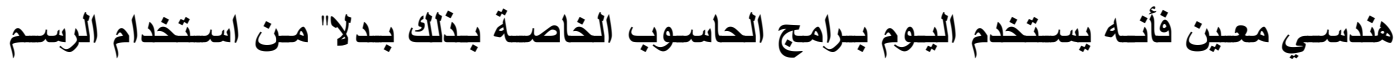
والتخطيط على الورق الذي يتطلب الكثير من الجها والوقت ، ولعلاج آلام الكلى وتفتيث الحصى الكلوي فأن الطبيب يستخدم جهاز الليزر كوسيلة مساعدة لذلك بـلا" من اجراء العملية الجراحية ،كما ان وسائل الاتصال السريع بالبريد الالكتروني قد وفرت على سـاعي البريد الوقت والجهد في نقل الرسائل التي قد تستغرق اسابيع للوصول الى اصحابها بأتباع وسائل الاتصال التقليدية . 


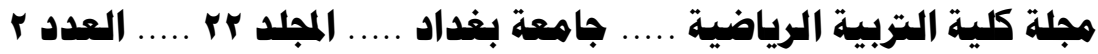

كمـا أن هـا التطور العلمـي يظهر جليـا" في المجـال الرياضـي مـن حيـ التجهيزات والادوات الرياضية التي ساهمت بشكل واضـح في رفع قابليات وقدرات الفرد الرياضسي في تحقيق

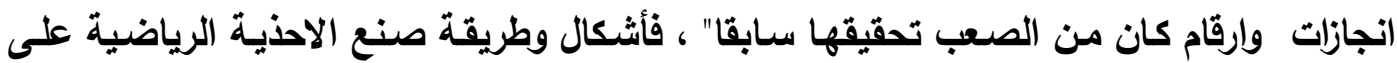
سبيل المثال اخذت بالتنوع والاختلاف على اسـاس نوع الفعالية فالربـاع يستخدم نـوع معين من الاحذية تختلف في تصميمها وشكلها عن تلكا التي يستخدمها الملاكم او عداء المسافات القصيرة ، وهكا بالنسبة الى الالبسـة الرياضية والادوات المساعدة المستخدمة في التدريب ، ففي تدريب حركات الجمناستك تستخدم ادوات واجهزة مساعدة لاتقان الحركات الصعبة والخطرة على اجهزة العلق او المتوازي وحصـان القفز ، وفي كرة القدم اصبح من الملاحظ استخدام كرات التدريب الثقيلة لزيادة قوة تسديدات اللاعب . وفي مجال رياضة السباحة فأن التطور لم يقتصر على التجهيزات والالبسة التي يرتديها السباح من حيث نوعية اغطية الرأس والمايوهات المستخدمة فحسب بل يضاف الى ذلك وسـائل التدريب المتنوعة والمتعددة الاغراض التي تسخر جميعها خـلال مراحل تدريب السباح لمساعدته

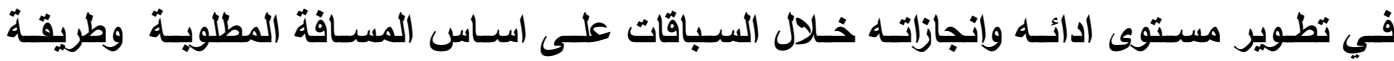
السباحة ، فمن الملاحظ في الاونـة الاخيرة تركيز مدريوا السباحة في العالم على استخدام الواح

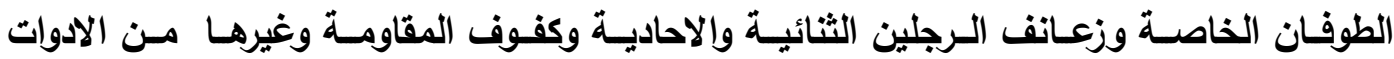
والاجهزة المسـاعدة التـي تعمل على زيـادة المقاومـات خـلال التـريب ويالتـالي تطوير الصـفات الاساسية التـي تتطلبها كل فعاليـة مـن فعاليـات رياضـة السـباحة ، فسباح المسـافات القصسيرة يسـتخدم تلكـ الادوات بطرق تـدريب وشـدد تختلف عن تلكـ التـي يسـتخدمها سـباح المسـافات المتوسطة والطويلـة ، كمـا ان كيفيـة استخدام تلكـ الادوات المسـاعدة يختلف ايضـا" حسب نـوع السباحة المعنية فسباح الحرة يستخدمها بطريقة تختلف عن كيفية استخدامها قبل سباح الفراشـة والصدر والظهر ... وهكذا حسب متطلبات كل فعالية ، ومن هنا تأتي اهمية بحثنا هذا في بيان اهمية التركيز على نوع معين من تلك الادوات الا وهي زعنفة الرجلين الاحاديـة من حيث تأثيرها في مستوى انجاز فعالية ـه م سباحة فراشة ومقدار التطور في انجاز السباح الذي يمكن ان ينتج عن التركيز على استخد/مها في التدريب . 
على الرغم من التطور الكبير في الاجهزة والوسائل والادوات التدريبية المستخدمة من قبل سباحي الاول المتقدمة ، وعلى الرغم من امتلاك اتحاد السباحة العراقي مدربين اكفاء وذوي خبرة

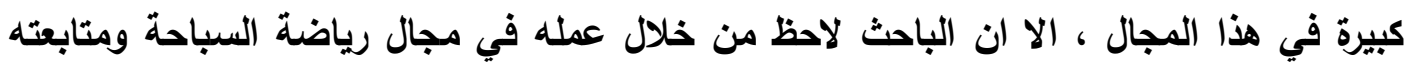

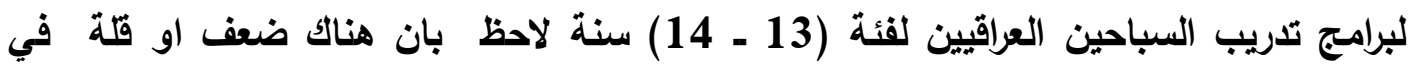
استخدام المدربين للوسائل والادوات المساعدة في التدريب ولاسبيما (زعنفة الرجلين الاحادية وكفوف السباحة) ويشكل خاص مع هذه الفئة من سباحي فعالية هم فراشة ، اذ يعزو الباحث

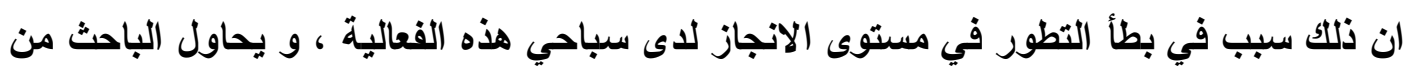
خلال بحثه هذا بيان الهمية وتأثير وسائل التدريب موضوع الدراسة في تطوير مستوى الانجاز في

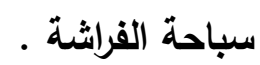

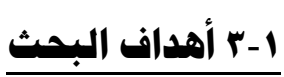

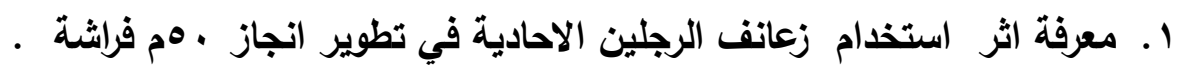

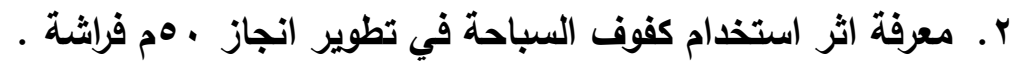

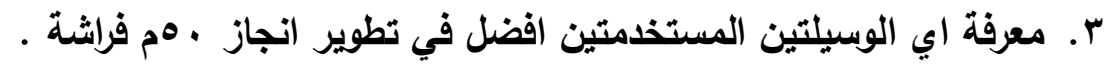

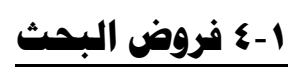

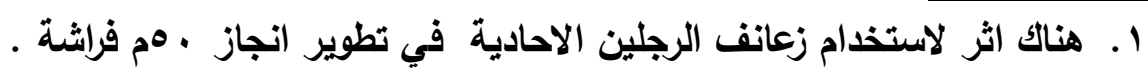

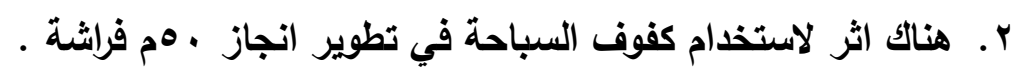

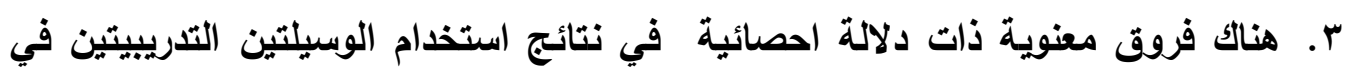

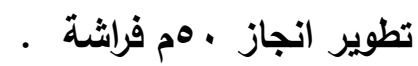

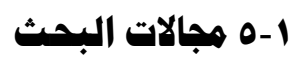

1-1 - المجال البشري : تألفت عينة البحث من 12 سباح من سباحي الاتحاد العراقي للسباحة

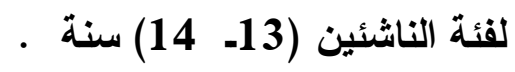

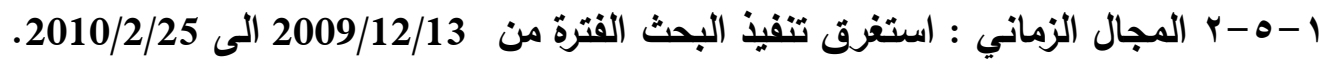

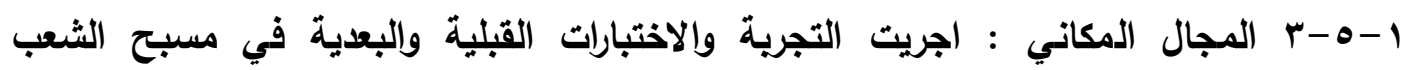

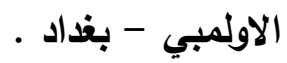
1-1 تحديد الصططات 


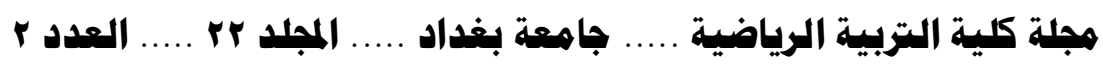

1 ـ زعنفة الرجلين الاحادية : تدعى احيانا" بـ (زعنفة الغطس) وهي عبارة عن زعنفة من المطاط المرن يتم ارتدائها بالقدمين معا" بحيث تكون متلاصقتين اثثاء الاداء ، تعمل

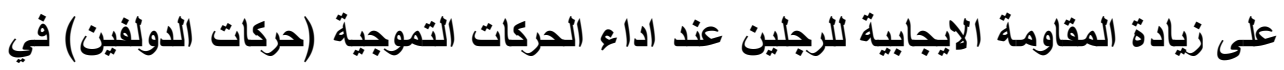
سباحة الفراشة ، وتكون بقياسات مختلفة حسب حجم القدمين والفئة العمرية التي ينتمي اليها السباح (اليباح r. كفوف السباحة : عبارة عن كفوف بلاستيكية صلبة مزودة بحلقات مطاطية مرنة لتثبيتها على باطن اليدين ، وتكون مقوسة الشكل ويحتوي سطحهاعلى ثقوب خاصة تساعد على بلى تحقيق المسارات القوسية للأراعين داخل الماء ، تعمل الكفوف على تسليط مقاومات ايجابية على الأراعين اثناء حركتها داخل الماء عند اداء فعالية سباحة الفراشة او اي نوع من انواع السباحة الاخرى (حرة ـ ظهر - صدر) ، وتكون بقياسات مختلفة وحسب حجم يد السباح والفئة العمرية و التي ينتمي اليها ـ التئ

\section{البـباب الثانــي}

r r r الدراسات النظرية

r-1 القوانين والمقاومات الخاصة في السباحة

على الرغم وجود عدد كبير من البحوث والدراسات التي تناولت موضوع القوى المؤثرة على الجسم اثناء السباحة الا انه لم يتحدد بالضبط " ما القوانين التي تدفع جسم السباح وتحركه داخل الماء "(1) ، اذ اثبتث البحوث ان هناك عدة قوانين تؤئز في قوة الدفع ولكن لم يثبث احدها بشكل نهائي ، فبعض الباحثين أكد على قاعدة برنولي واتخذت كقاعدة للقوى المحركة والتي تتص على ان ضغط السائل يقل على الجسم عندما تزداد سرعة انسيابيته ، في حين يرى البعض الاخر من الباحثين ان قانون نيوتن الثالث (قانون الفعل ورد الفعل) هو الاساس في حركة السباح ، وفي الحقيقة هناك تطابق نوعا ما بين قاعدة برنولي والقانون المذكور ف "عندما يدفع السباح الماء الى الخلف فأن ذلك سوف يعجل تقدم الجسم الى الامام بمقدار القوى

(1) Costill , DL .Maglischo EW , Richardson AB :Swimming .Blachwell Scientific. London .1992. p50 


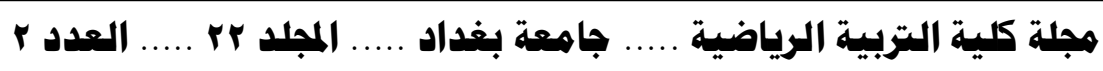

المحركة ..... وللوصول الى اقصى كفاءة للافع ،يجب دفع كمية كبيرة من الماء لمسافة قصيرة

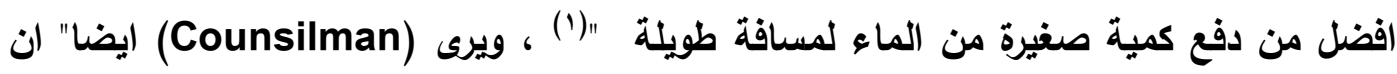
زيادة سرعة السباح تعتمد على العوامل الآتية : 1. تقليل المقاومة المائية ، وذلك عن طريق اتخاذ الوضع الانسيابي للجسم بأتجاه الحركة ،ومنع حدوث الاوامات الناتجة بسبب الوضع غير الصحيح لمفاصل الجسم . r ـ زيادة القوى الدافعة والتي تنشأ من جراء حركات الذراعين وضريات الرجلين في بعض الاحيان ، حيث تقوم الأراعين بالحركة على شكل حرف (S) والتي تثبه حركة المروحة في القوارب وذلك لدفع الماء الى الخلف والتي تسبب دفع الجسم للامام . r. الريط بين العاملين اعلاه ، ويعتمد على تطبيق الاسلوب الجيد (التكنيك) في تنفيذ حركات الأراعين والرجلين ويما تتلائم مع المواصفات البدنية للسباح وقابليته على الطوفان التي ترتبط بالكثافة الدهنية للجسم ووزن العظام •

\section{r-r}

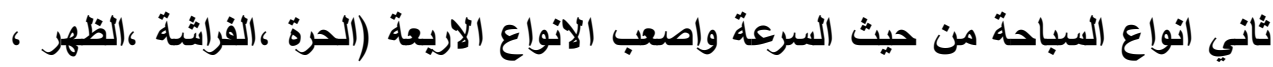
الصدر) من حيث الاداء والجها البذني المبذول وهي من السباحات الاكثر تميزا" في المنافسات هات وقد تطورت عام · ب9 ام واعتبرت المظهر الجديد الاسرع لـ (سباحة الصدر) والذي تكون فيه الأراعين خارج الماء سوية وكالتصفيق المزدوج لحركة التوقيتية والتي انتجت سباحة لاتثبه سباحة الصدر ، وهذه الاختلافات جعلتها تختلف عن سباحة الصدر . ويهذا ولات سباحة جديدة

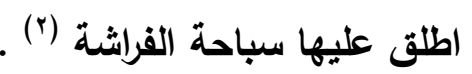
كما ان سباحة الفراشة تسمى ايضا" سباحة الدولفين نظرا لحركة الرجلين في هذا النوع من انواع السباحة والذي تشبه حركات الزعنفة الأنبية للاولفين ، ويرى علي مروش ان سباحة

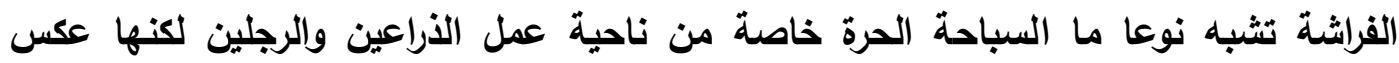

(1) Costill , DL .Maglischo EW , Richardson AB :Swimming .Blachwell Scientific. London .1992. p50 .

(2) Counsilman .E.James:The Science of Swimming. Prentice. Hall , Inc. 1968. p26 . 
السباحة الحرة فأنهما تعملان في آن واحد وليس بطريقة تناويية واصل هذه التقتية في الحركة هي اصلا من حركات السباحة على الصدر اذ كان عمل الأراعين على شكل فراشة لكن عمل

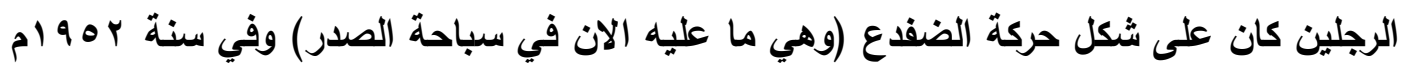
قامت الفدرالية العالمية للسباحة (Fina) بالتمبيز والفصل بين النوعين واصبح قانون استعمال حركات الاولفين للرجلين وحركات الفراشة للاراعين (') ، اما من ناحية التشابه بين سباحتي لاتين الفراشة والصدر فأن وضع الجسم في السباحتين يعكس هذا التشابه ، اذ يكون الوضع الافقي للجسم غير ثابت في النوعين وانما يتغير بأستمرار في كل دورة كاملة للاراعين والجسم يكون في حركة تموجية مستمرة الى الاعلى والاسفل حسب المرحلة الحركية (والجسم يكون في حركة

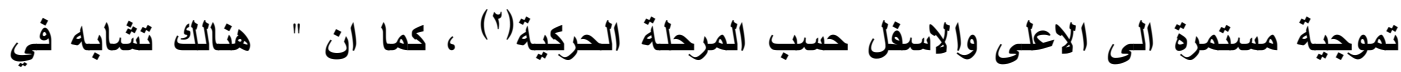
عمليتي الشهيق والزفير بي الفراشة والصدر ، اذ يبدأ الشهيق عندما تكون الأراعان في وضع الخع الارجاع (خارج الماء) من خلال الفم وذلك برفع الرأس الى الاعلى قليلا (ورفع الحنك الى الامام ) ويذلك يخرج الفم فوق سطح الماء ـ اما عملية الزفير فبطرح الماء مما يسلط على السباح مقاومة من قبل الماء ويتطلب ذلك عمل عضلات الزفير الاضافية لأخراج الهواء من الرئتين

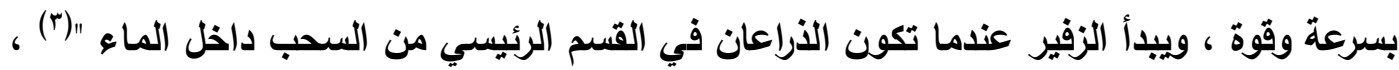
ويشير القانون الدولي للسباحة الى انه " يجب ان يكون الجسم على الصدر في كل الاحيان ماعدا عند تنفيذ الدوران ينبغي ان تكون الاكتاف بمستوى واحد مع سطح الماء منذ بداية اول ضرية للأراعين ، ويعد كل دوران وينبغي البقاء على تلك الوضعية حتى الدوران او النهاية ، اي لايسمح باللف على الظهر في اي وقت ، وكذلك يؤكد قانون سباحة الفراشة ان يجب تقديم كلتا الأراعين للامام معا فوق سطح الماء وترجع بشكل متزامن ، ويجب ان تنفذ جميع الحركات

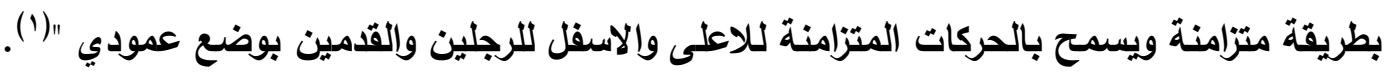

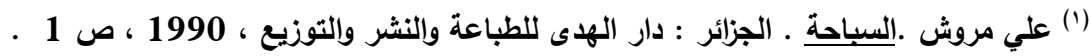

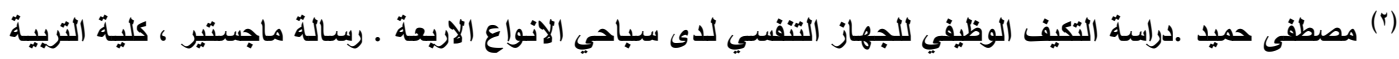

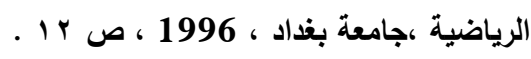

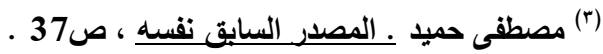

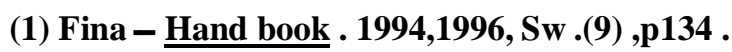




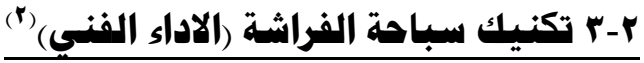 \\ ا 1 وضع البسميم}

يكون وضع الجسم في سباحة الفراشة في تغير مستمر خلال كل دورة كاملة للأراعين حيث يكون الجسم في حركة تموجية مستمرة الى الاعلى والاسفل وان القوة الحركية للجسم لا تحدث من الاطراف فقط بل يشارك في ذلك ايضا" كل من العمود الفقري والوررك ، وتؤدسحركة الرأس للاسفل وللاعلى وتكون الاذنان بين العضدين عند امتداد الأراعين . r. تركة الذراعين تتحرك الأراعان في حركة دائرية معا من مفصل الكتف وعليه فأن حركة الأراعين تكون على شكل قوس دائري تقريبا.

ويبدأ عمل الذراعين عند دخولهما الماء حيث تكون المسافة بينهما بعرض الكتفين تقريبا في نقطة امام منتصف الجسم مع انثناء قليل في مفصل المرفق ثم تمتد الأراعان داخل الماء وتتحرك الى الامام والاسفل ، ثم تبدأ بعد ذلك عملية السحب بعد ان يتم فتح الذراعين جانبا اسفل حيث تكون المسافة بينهما اكبر بقر عض الكتفين مرتين تقريبا، ويكون الشد او السحب على شكل حرف (S) مستطالة مع الاحتفاظ بالمرفقين مرتفعين اثناء الثد حيث يثنى المرفقين للاعلى 90 درجة تقريبا ، بعدها تدفع اليدان الماء للخلف والخارج بعيدا عن الفخذين عند نهاية الثد اوالسحب ، بعد ذلك تخرج الأراعان من خلال نقلهما من الخلف الى الامام والاعلى عن طريق مفصل الكتفين وتتحرك الأراعان فوق سطح الماء مباشرة ويكون المرفقان مستقيمين ومرتفعين قليلا ثم تدخل الذراعان الماء مرة اخرى لتعاود العملية نفسها وهكذا يستمر عمل الذراعين . r. ت ضربات الرجلين يؤدي السباح في سباحة الفراشة ضريتين بالرجلين مع كل دورة للأراعين حيث تكون الضربة الاولى قوية للاسفل وهي الضربة الكبرى والتي تتم بلخول الذراعين للماء مباشرة حيث

(†) اسامة كامل راتب وعلي محمد زكي • الاسس العلمبة للسباحة .تدريب ـ تخطيط ـ برامج ـ تحليل حركي ـ القاهرة : دار الفكر العربي ، 1998 ، ص 243 ـ 240 
تحدث عندما يكون السباح في ابطأ سرعة اثناء دورة الأراعين وهي تساعد على رفع الورك وزيادة في انسيابية الجسم اثناء سحب الذراعين داخل الماء . اما الضرية الثانية للرجلين فتسمى بالضرية الصغيرة وهي اقل قوة واصغر وتؤدى اثناء المرحلة الاخيرة من عملية سحب الأراعين وهي تحافظ على رفع الورك اثناء السباحة ، اذ تؤدى الحركة للاسفل من مفصلي الفخذين وتثنى الركبتان قليلا عند حركة الرجلين للاسفل وخروج كعبي القدمين من الماء . القماء

ع. التوافق من

عندما يقوم السباح بنقل الذراعين من الخلف الى الامام اي عندما تكون الذراعان فوق سطح الماء تبدأ عملية الثهيق وذلك بثني الرأس من مفصل الرقبة الى الخلف قليلا حيث يخرج الفم فوق سطح الماء ، وعند دخول الأراعين في الماء ياخل الرأس معها وتؤدى اول ضرية للرجلين للاسفل وهي الضربة الكبرى ، ويعد ذلك يقوم السباح بعملية السحب بالذراعين تتم عملية الزفير داخل الماء وعند المرحلة الاخيرة من سحب الأراعين تؤدى الضربة الثانية بالرجلين للاسفل بهل وهي الضرية الصغيرة ، ويكون التفس مع كل دورة بالأراعين يحقق الايقاع الامثل فضلا عن تحقيق الحركة التموجية للجسم والمطلوية في هذا النوع من السباحة .

\section{البــاب الثالهــث}

r- منهه البحث واجزsاته الميدانية

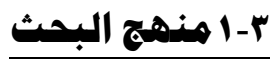

استخدم الباحث المنهج التجريبي بطريقة المقارنة لملائمته مشكلة البحث .

قام الباحث باختيار 13 سباح من سباحي الاتحاد العراقي للسباحة (اندية بغداد) اذ تعمد اختيارهم من الفئة العمرية (13 - 14) سنة ومن سباحي فعالية 50م فراشة وكذلك اعمار وقياسات جسمية متقارية ، ويعد اجراء اختبار سباحة ، مم فراشة تم استبعاد سباح واحد لوجود فارق 


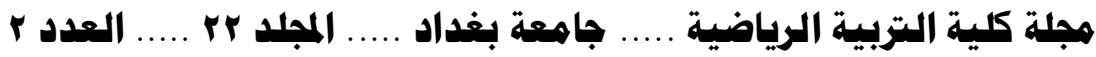

كبير بين مستوى ادائه وانجازه عن بقية السباحين ليكون مجموع عينة البحث 12 سباح متقاربين في العمر الزمني والقياسات الجسمية اذ تراوحت اوزانهم بين (54 ـ 59)كفم في حين تراوحت اطوالهم بين (1.62 1.65)متر • ويهذا فقد كانت العينة متجانسة من حيث العمر والطول والوزن ، اما من حيث مستوى الانجاز الرقمي لسباحة 50م فراشة فقد اكدت نتائج الاختبار القبلي لـ50م فراشة عدم وجود فروق معنوية بين افراد العينة وكما هو موضح في الجدولين رقم (1) و(2) لذا تعد العينة متكافئة ايضا"من حيث المستوى الرقمي لفعالية 50م فراشة ، ويعد التأكد من تجانس وتكافؤ العينة تم تقسيمها عشوائية الى ثلاثة مجاميع متساوية (مجموعتين تجريبية وإخى ضابطة ) حيث ضمت كل مجموعة 4 سباحين وكما يلي :

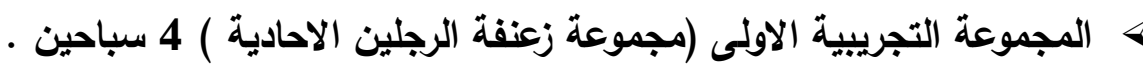

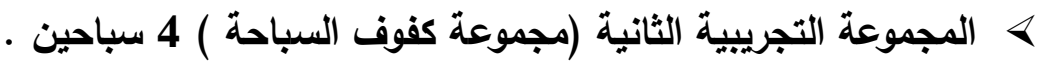
\& المجموعة الضابطة ( التي لم تستخدم الوسيلتين اعلاه ) 4 سباحين .

$$
\text { (1) (1) (1) (1) }
$$

الاوساط الحسابية والانحرافات المعيارية في الاختبار القبلي لفعالية 50م فراشة لافراد عينة البحث

\begin{tabular}{|c|c|c|}
\hline الانحراف المعياري & الوسط الحسابي & المجاميع \\
\hline 0.70 & 40.70 & مج.اولى (الزعنفة الاحادية ) \\
\hline 0.89 & 41.10 & مج. ثانية (كفوف السباحة) \\
\hline 1.37 & 40.70 & المجموعة الضابطة \\
\hline
\end{tabular}

جدول (2)

نتائج تحليل التباين (F) في الاختبار القبلي لفعالية 50م فراشة لمجاميع البحث الثلاثة

\begin{tabular}{|c|c|c|c|c|c|c|c|}
\hline \multirow{2}{*}{ النتيجة } & \multicolumn{2}{|c|}{ قيمة F } & \multirow{2}{*}{ متوسط } & \multirow{2}{*}{ الحرية } & \multirow{2}{*}{ المربعات } & \multirow{2}{*}{ مصدر } & \multirow{2}{*}{ الاختبار } \\
\hline & الجدولية & المحتسبة & & & & & \\
\hline عشوائي & 4.25 & 0.33 & 0.2 & 2 & 0.4 & بين & 50 \\
\hline
\end{tabular}




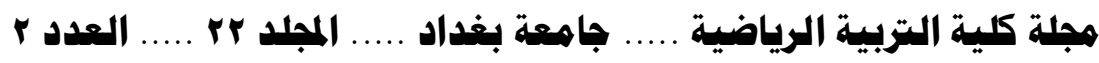

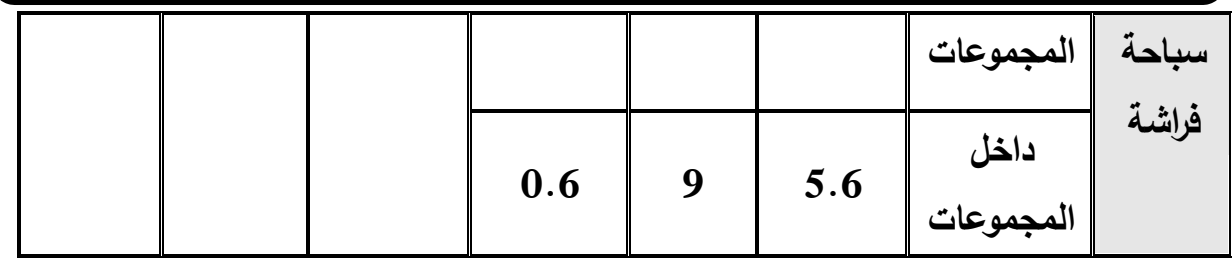

r-r r ادوات البحث

زعانف الرجلين الاحادية .عدد 5

كفوف السباحة . عدد 5

الوإح طوفان

ه جهاز لقياس الوزن والطول ياباني الصنع .

> ماعات توقيت يدوية عدد 3 ـ

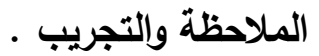

المصادر العلمية (الكتب والمرجع) .

فريق العمل المساعد " فئ"

المعالجات الاحصائية .

\section{r-ع التبربة الاستطلاعية}

لغرض تنظيم وتنسيق مجريات البحث وتحديد السلبيات والمعوقات التي قـ ترافق تجرية البحث الرئيسية اجرى الباحث تجريته الاستطلاعية على عينة صغيرة من سباحي نادي الجيش (5) سباحين تم اختيارهم بالطريقة العشوائية من غير السباحين المشاركين في مجموعات البحث الثلاثة ، حيث استغرقت هذه التجرية اريعة ايام وقد تم اجرائها قبل اسبوع من بدأ تجرية البحث

• (تألف فريق العمل المساعد من :

> السيد ـ محمد عبد الاله (مدرب المنخب العراقي للسباحة للشباب)

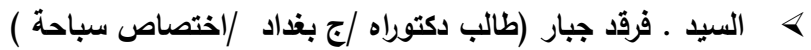
ه السيد يسار صبيح (ماجستير سباحة / مدرب المنتخب العراقي للمعوقين /سباحة) 


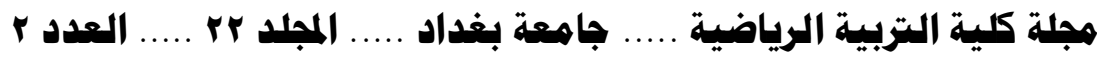

الرئيسية اي بتاريخ ( 2009/12) في مسبح الثبع الاولمبي المظلق في بذاد ، وقد ساعدت التجرية الاستطلاعية في اختبار صلاحية زعانف الرجلين الاحادية وكفوف السباحة المستخدمة وكذلك تحديد وتنظيم الوقت المخصص للتدريب عليها ضمن الوحدة التدريبية اضافة الى اختبار صلاحية ساعات التوقيت اليدوية المسخدة من خلال اجراء اختبارات بينية للسباحين

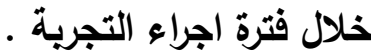

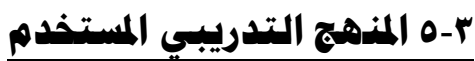

من خلال متابعة الباحث الوحدات التدريبية لسباحي اندية بذاد من فئة الناشئين(13ـ 14) سنة

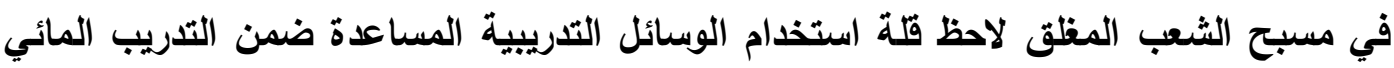
ولاسيما (زعانف الرجلين وكفوف السباحة) وخاصة في تدريبات سباحي الفراشة ضمن الفئة المذكورة على الرغم من توفر الوسائل المذكورة لاى الاتحاد العراقي المركزي للسباحة ، وعليه ولأعتقاد الباحث بأهية مثل هذه الوسائل ودورها في تطوير الانجاز الرقمي لسباحة المسافات

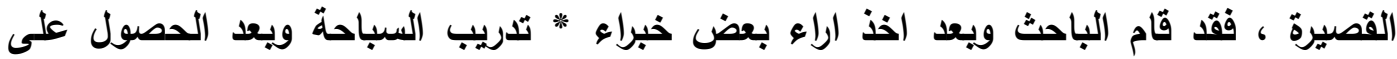
موافقة المدربين المختصين قام بأجراء بعض التعديل على المنهج التدريبي المستخدم والمتفق عليه في اتحاد السباحة العراقي ، اذ تضمن هذا التعديل ادخال تمارين اوتكرارات لسباحة مسافات معينة بأستخام (زعانف الرجلين وكفوف السباحة ) ضمن القسم الرئيسي من الوحدة التدريبية

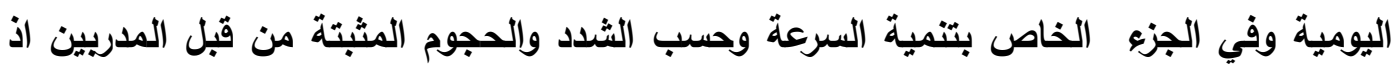

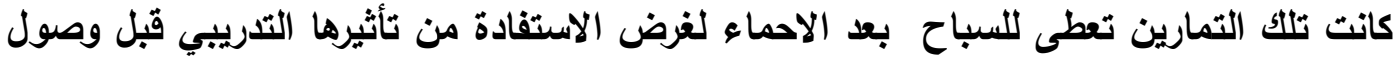
الجسم الى مرحلة التعب نتيجة مفردات المنهج الاخرى ولان الجهاز العصبي يلعب دورا كبيرا فيها

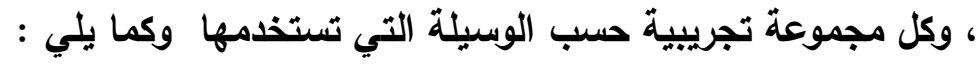
همج. اولى (هجموعة زعنفة الرجلين الاحادية)

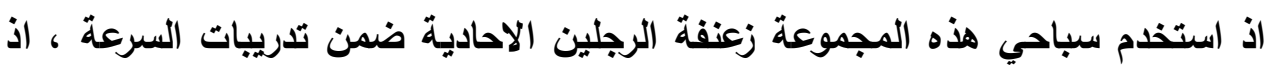
كان السباح يؤدي التكرارات المحددة له ضمن الوحدة التدريبية فيمكك بلوح الطوفان باليدين

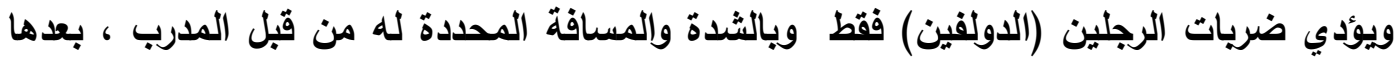
يستأنف السباح التمارين والتكرارت الاخرى الخاصة بمنهجه التدريبي . 
هـ ثمانية (هجموعة كفوف السباحة)

اذ استخدم سباحي هذه المجموعة كفوف السباحة ضمن تدريبات السرعة ، اذه اذ كان

السباح يؤدي التكرارات المحدة له ضمن الوحدة التدريبية فيضع لوح الطوفان بين رجليه ويركز

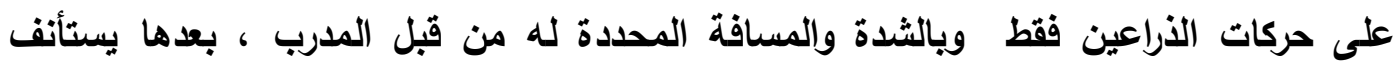
السباح التمارين والتكرارت الاخرى الخاصة بمنهجه التدريبي · مرات علما ان سباحي المجموعة الضابطة لم يستخدموا اي من الوسيلتين اعلاه خلال الوحدات التدريبية واقتصر تدريبيهم على الثدد والتكرارات المحددة لهم ضمن المنهج دون الستخدام الزعانف او كفوف السباح ، كما ان من الجدير بالذكر ان المجاميع الثلاثة استخدمت نفس الحجوم والتكرارات والثدد التدريبية ووفق نفس الطرق التدريبية المتبعة ضمن منهج تدريب سباحي الفراشة فقد تضمن المنهج ثلاثة وحدات تدريبية اسبوعية ولمدة ثمانية اسابيع تم التدرج فيها بالحمل التدريبي الكلي وفق الاسس العلمية المتبعة وقد تم البدأ بتطبيق المنهج من الفترة 2009/12/13 2009 ولغاية الفترة 2010/23 مئي

r-7 الاختبار البـعدي

بعد انتهاء فترة تطبيق المنهج التدريبي لمجاميع البحث الثثلاثة التي استغرقت (9) اسابيع ، تم اجراء اختبار بعدي لسباحة 50م فراشة لافراد عينة البحث كافة ، حيث تم اجراء الاختبار بتاريخ 2010/25/ قبل الميقاتيين الثلاثة الموجودين عند نهاية الحوض اذ تم احتساب متوسط الاوقات الثلاثة لاستخراج الاتجاز الرقمي لكل سباح في سباحة 50م فراشة والذي سجل في استمارة الاختبار تحت اشراف الباحث ، ويعدها تمت معالجة البيانات احصائيا" للتوصل الى النتائج .

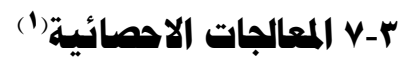

تضمن البحث استخدام المعالجات الأحصائية التالية :

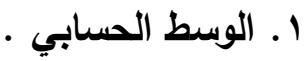

(1) عبد الرحمن علس وخليل يوسف .الاحصاء للباحث في التربية والعلوم الانسانبة . عمان : دار الفكر للنشر والتوزيع ، 1988، ص107 لرعن 
هبلة كلية التربية الرياضية .... جاهعة بغداد ..... المبلد r ..... العدد r r....

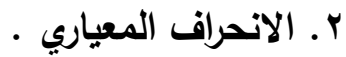

r. أختبار(T) للعينات المتناظرة

L.S.D اختبار اقل فرق معنوي

\section{البـاب الرابـع}

צ- عرض النتائج وتهليلها ومنـاقشتهـا

ع-1 عرض نتائج عينة البحث في اختبار 50م سباحة فراشة وتصليلها

فيما يلي عرض وتحليل لنتائج اختبار معنوية الفروق بين الاختبارين القبلي والبعدي لمجاميع البحث والمتثل بأختبار (T) ، واختبار تحليل التباين (F) واختبار اقل فرق معنوي : لافراد العينة في اختبار 50. (L.S.D) ع-1-1 عرض وتهليل نتائج اختبار (T) المعنوية الفروق بين نتائج الاختبارين القبلي والبعدي لئي لسباحة 50م فراشة لمجاهيع البمث الثلاثة

جدول (3)

الاوساط الحسابية والانحرافات المعيارية وقيم T المحتسبة والجدولية ومعنوية الفروق

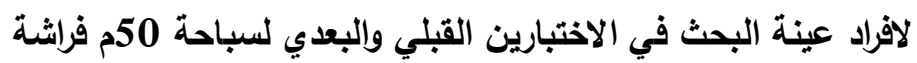

\begin{tabular}{|c|c|c|c|c|c|c|c|c|}
\hline \multirow{2}{*}{ النتيجة } & \multicolumn{2}{|c|}{ قيمة T } & \multirow[t]{2}{*}{ ن } & \multicolumn{2}{|c|}{ البعدي } & \multicolumn{2}{|c|}{ القبلي } & \multirow{2}{*}{ المجاميع } \\
\hline & الجدولية & المحتسبة & & $\varepsilon$ & س'--- & $\varepsilon$ & س- & \\
\hline معنوي & 3.18 & 3.69 & 4 & 0.0 & 38.80 & 0.70 & 40.70 & مج. تجريبية اولى \\
\hline
\end{tabular}




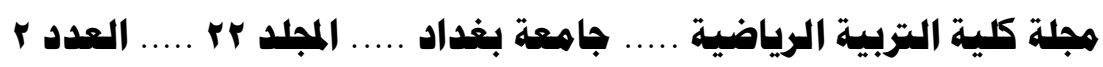

\begin{tabular}{|c|c|c|c|c|c|c|c|}
\hline & & & & & & & (زعانف احادي) \\
\hline معنوي & 3.93 & 4 & 0.77 & 40.20 & 0.89 & 41.10 & مجه. تجريبية ثانية \\
\hline معنوي & 8.5 & 4 & 0.89 & 40.50 & 1.89 & 40.70 & المجموعة الضابطة \\
\hline
\end{tabular}

يبين الجدول (3) الاوساط الحسابية والانحرافات المعيارية في قيم الانجازات الرقمية القبلية والبعدية في اختبار سباحة 50م فراشة لاى سباحي المجاميع الثلاثة ، اذ يلاحظ من خلال الجدول اعلاه بأن المجموعة التجريبيةالاولى التي استخدمت زعانف الرجلين الاحادية في تدريبها قد حققت وسطا" حسابيا" قبليا" بلغ (40.7) في حين كان انحرافها المعياري ( 0.70) اما في الاختبار البعدي فقد حققت وسطا" مقاره (38.80) ويأنحراف معياري قدره (0.0) ومن خلال معالجة البيانات احصائيا" فقد بلغت قيمة T المحتسبة بين القياسات القبلية والبعدي لهذه المجموعة (3.96) ويمقارنة هذه القيمة مع القيمة الجدولية البالغة (3.18) يظهر بأن الفرق

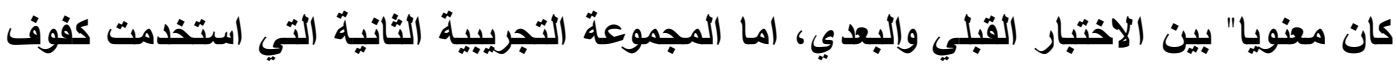
السباحة في التدريب فقد حققت في الاختبار القبلي وسطأ مقداره (41.10)(ما انحرافها المعياري فقد كان بمقدار (0.89) في الوقت الذي حققت نفس المجموعة وسطا حسابيا" بلغ (40.20) وانحرافا" بلغ (0.77) في الاختبار البعدي لسباحة الفراشة ، وعند معالجة هذه البيانات احصائيا" تبين ان قيمة T المحتسبة كانت (3.93) ويمقارنة هذه القيمة مع القيمة الجدولية البالغة (3.18) يتبين ان الفرق كان معنويا" ايضا" بين الاختبارين القبلي والبعدي لنتائج هذه المجموعة ، اما المجموعة الثالثة الضابطة فقد كان وسطها الحسابي القبلي (40.70) في حين بلغ انحرافها المعياري القبلي (1.89) اما نتائجها البعدية فقد حققت وسطا" حسابيا" بلغ (40.50) وانحرافا" معياريا" قره (0.89) ، اما قيمة T المحتسبة بين البيانات القبلية والبعدية لهذه المجموعة فقد بلغت (8.5) ويمقارنتها مع القيمة الجدولية البالغة (3.18) يتضح بأن الفروق كانت معنوية بين هذه النتائج ، علما ان درجة الحرية كانت (ن - 1 = 3) و مستوى الدلالة 


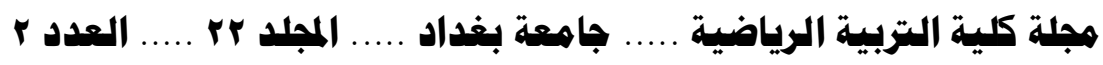

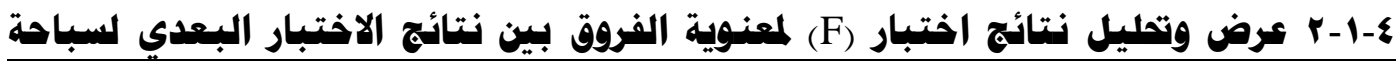

50م فراشة لمباهيع البحث الثلاثة

لمعرفة فيما اذا كان هناك فروق احصائية معنوية ذات دلالة احصائية بين المجموعات الثلاثة في نتائج الاختبار البعدي لسباحة 50م فراشة ، فقد تم معالجة البيانات واستخراج نتائج اختبار تحليل التباين واحتساب قيمة (F) ومقرانتها بالقيمة الجدولية كما هو مبين في الجدول رقم

(4) الأي يشير الى وجود فرق معنوي بين نتائج المجموعات الثلاثة في الاختبار وكما يأتي :

جدول (4)

نتائج تحليل التباين (F) لمجموعات البحث الثلاثة في الاختبار البعدي لسباحة 50م فراشة

\begin{tabular}{|c|c|c|c|c|c|c|c|}
\hline \multirow{2}{*}{ النتيجة } & \multicolumn{2}{|c|}{ قيمة F } & \multirow{2}{*}{ متوسط } & \multirow{2}{*}{ الحرجات } & \multirow{2}{*}{ المربعات } & \multirow{2}{*}{ مصدر التباين } & \multirow{2}{*}{ الاختبار } \\
\hline & الجدولية & المحتسبة & & & & & \\
\hline \multirow{3}{*}{ المغرق } & \multirow{3}{*}{4.25} & \multirow{3}{*}{7.40} & 3.48 & 2 & 6.96 & المجموعات & \multirow{2}{*}{ سباحة } \\
\hline & & & 0.47 & 9 & 4.24 & المجموعات & \\
\hline & & & & 11 & 11.2 & & \\
\hline
\end{tabular}

يظهر الجدول (4) نتائج تحليل التباين (F) لنتائج الاختبار البعدي لسباحة 50م فراشة لاى مجاميع البحث الثلاثة ، حيث كان مجموع المريعات بين المجموعات (6.96) ودرجة حرية (2) ومتوسط مريعات بين المجموعات بلغت قيمته (3.48) ، في حين كان مجموع المريعات داخل المجموعات بقيمة (4.24) ويدرجة حرية (9) في الوقت الأي بلغت قيمة متوسط الريعات داخل المجموعات (F.47) ، اما قيمة (F) المحتسبة فقد كانت (7.40) ويمقارنة هذه القيمة مع

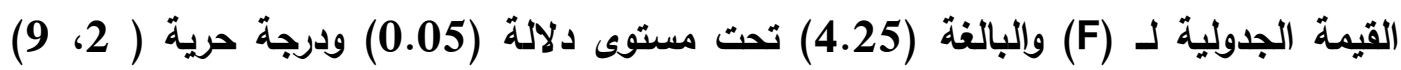
يظهر بأن الفرق معنوي دال احصائيا" بين نتائج الاختبار البعدي للمجاميع الثلاثة في اختباركم 50م فراشة . 


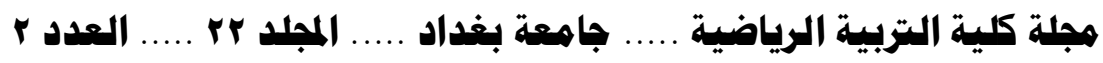

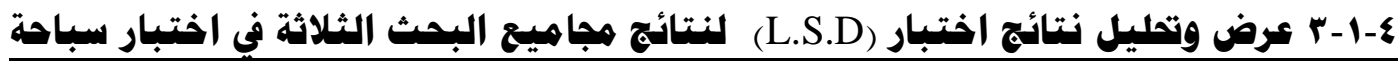

50 مث فراشة

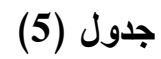

الفروق بين الاوساط الحسابية وقيمة (L.S.D) لنتائج المجاميع الثلاثة في اختبار 50م فراشة

\begin{tabular}{|c|c|c|c|c|}
\hline L.S.D & $\begin{array}{c}3 \text { س } \\
40.5=-5\end{array}$ & $\begin{array}{c}2{ }^{2} \\
40.2=-2\end{array}$ & $\begin{array}{c}1 \\
38.8={ }^{-} \text {س }\end{array}$ & الاوساط الحسابية للمجاميع \\
\hline \multirow{3}{*}{1.08} & $\begin{array}{l}1.7 \\
\text { معنوي }\end{array}$ & $\begin{array}{l}1.4 \\
\text { معنوي }\end{array}$ & - & سج. اولى (الزعانف) = 38.8 س \\
\hline & $\begin{array}{c}0.3 \\
\text { عشوائي }\end{array}$ & - & - & سج. ثانية (كفوف) = - 40.2 \\
\hline & - & - & - & سج. ثالثة (ضابطة) \\
\hline
\end{tabular}

بعد تطبيق اختبار تحليل التباين (F) لنتائج عينة البحث في الاختبار المستخدم والتوصل الى معنوية الفروق المعنوية بين نتائج الاختبار البعدي للمجموعات الثلاثة لجأ الباحث الى استخدام اختبار اقل فرق معنوي (L.S.D) لتحديد اماكن هذه الفروق اي لمعرفة بين اي المجموعات يكمن الفرق ، اذ يلاحظ من خلال الجدول (5) ان قيمة (L.S.D) كانت (1.08)وعند مقارنتها مع قيمة الفروق بين الاوساط الحسابية لعينة البحث ، نجد ان الفرق يتحدد بين المجموعتين الاولى والثانية والاولى والثالثة وهي على التوالي (1.4) و (1.7) وهي اكبر من قيمة اقل فرق معنوي (L.S.D) اذ كان الفرق في الحالتين لصالح المجموعة الاولى ، الصى بينما لم يكن هناك فرق معنوي بين المجموعتين الثانية والثالثة هيث كان الفرق بين الاوساط

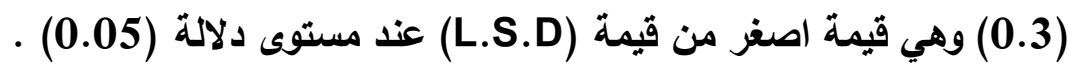

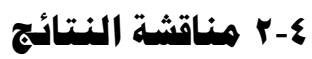




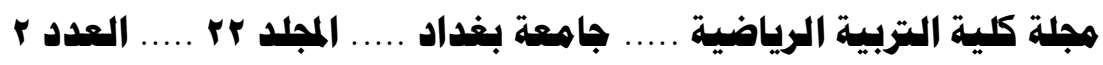

من خلال ملاحظة الجدول (3) يتبين ان الفروق كانت معنوية بين القياسات القبلية والبعدية للازمان المتحققة في اختبار 50م فراشة ، وهذه نتيجة طبيعية للتطبيق الصحيح للمنهج التدريبي وفق اسس علمية صحيحة ، اذ دل ذلك التحسن بالانجاز في الاختبار البعدي على ان الاساليب التدريبية المستخدمة من قبل افراد المجاميع الثلاثة كانت فعالة وايجابية في تطوير الانجاز حتى مع افراد المجموعة الضابطة اذ يرى الباحث ان هذا التطور في الانجاز كان نتيجة المواضبة على التدريب من قبل افراد عينة البحث ونتيجة التكيف الحاصل لاى افراد العينة في الاجهزة الوظيفية من جراء المجهود البذني المبذول خلال وحدات التدريب ضمن المنهج التدريبي المستخدم اذ ان " الكفاية البدنية للرياضيين قد تكون على درجة عالية او منخفظة تبعا للتدريب

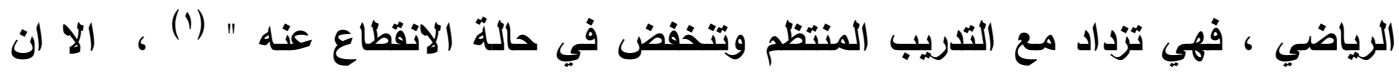
مستوى او مقار هذا التحسن او التطور في الانجاز كان متفاوتا" من مجموعة الى اخرى ، فمن خلال ملاحظة الجدول (4) يتبين ان هناك فروق معنوية بين نتائج الاختبار البعدي لمجاميع البحث كافة فقد ظهرت قيمة (F) المحتسبة اكبر من القيمة الجدولية لها ، ولتحديد مكمن الفرق ومعرفة افضل المجموعات من حيث التحسن بالانجاز فقد تم تطبيق قانون اقل فرق معنوي (L.S.D) استخدمت زعانف الرجلين كوسيلة مساعدة في تدريبها والمجموعة الضابطة التي لم تستخدم تلك لتك الوسيلة التدريبية ضمن المنهج ولصالح المجموعة الاولى ، كما ظهر الفرق ايضا" معنويا" بين المجموعتين الاولى (زعانف الرجلين) والثانية والثانية التي استخدمت كفوف السباحة كوسيلة تدريبية مساعدة ولصالح المجموعة الاولى يضا" ، ويعزو الباحث هذه الافضلية للمجموعة التجريبية الاولى الى استخدامها للزعانف الاحادية في التدريب حيث ساعدت تلك الزعانف في تطوير قوة ضريات الرجلين الدولفينية التي يكون لها الدور المهم في دفع الجسم الى الامام في سباحة الفراشة ، فضلا" عن دور الزعانف في تطوير مرونة الجذع والفقرات القطنية التي تعد من الصفات البذنية المهمة التي يحتاجها الجسم للانزلاق والاندفاع في الماء اثناء اداء سباحة الفراشة ، كما يرى الباحث ان استخدام الزعانف الاحادية في التدريب ساعد في تطوير قرة الفرد

(1) ابو العلا احمد عبد الفتاح. بيولوحيا الرياضة . القاهرة : دار الفكر للطباعة ، 1981 ، ص146 ـ 


\section{هجلة كلية التزبية الرياضية .... جاهعة بغداد ..... المبلد r...... العدد r ....}

على اداء متطلبات التريب والتكيف لها فقد شكلت الزعانف مقاومات اضافية على الجسم ودفعت السباح الى اداء متطلبات اكبر من متطلبات التدريب الاعتيادية التي يؤديها سباح المجموعة الثانية او المجموعة الضابطة الامر الأي ساهم ايضا" في تفوق افراد هذه المجموعة على افراد بقية المجاميع اذ ان " التكيف التدريبي يحصل عندما تكون متطلبات التدريب اكثر من المتطلبات الاعتيادية التي يلاقيها السباح عند المنافسة "(') ، وعلى اساس ذلك فقد تم تحقيق اهداف وفروض البحث في معرفة اثر استخدام الوسيلتين التريبيتن (الزعانف الاحادية وكفوف السباحة) في تطوير انجاز سباحة 50م فراشة ، وهل ان هناك فرق معنوي دال احصائيا بين نتائج استخدام الوسيلتين في التدريب إيبر

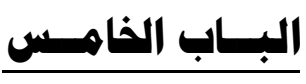

0- الاستتنتاجات والتوصيات

1-0 الاستنتتاجات

على ضوء البيانات المتحققة استتنج الباحث :

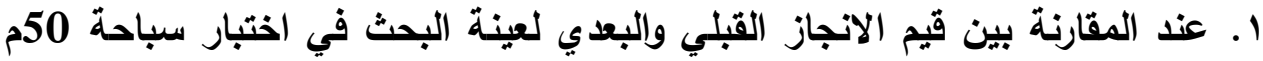

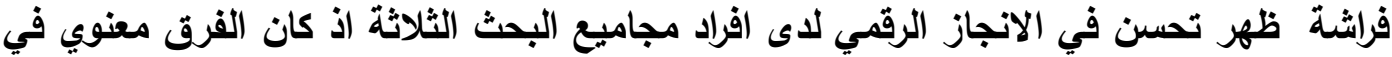
النتائج ولصالح القياس البعدي ، ويرجع هذا التحسن الى التأثير الايجابي للاسلوب التدريبي ملئي

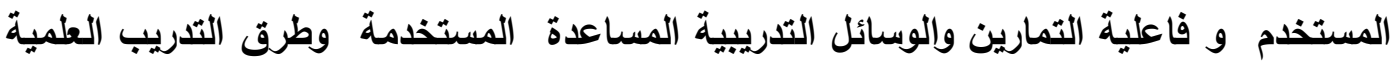

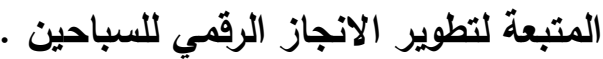
r. على الرغم من اتباع نفس اساليب وطرق التدريب من حيث الاوقات المخصصة التهئ

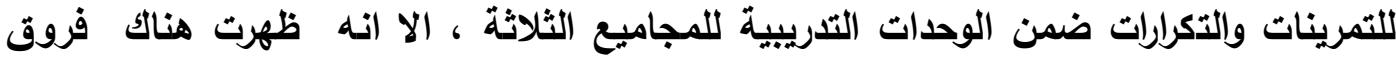

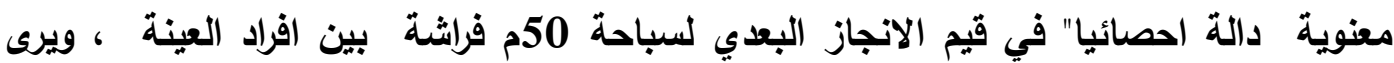

(1) Maglisho , E.W. : Swimming Faster, Mayfield Publishing Co. Ltd., California State University, 1982 , P. 303 . 
الباحث ان هذا التباين في الانجاز يعود الى تأثير وسائل التدريب المساعدة المستخدمة (الزعانف الاحادية وكفوف السباحة) اذ ساعدت تلكك الوسائل في تحسين الانجاز بالتئ

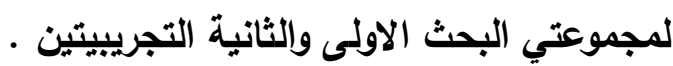

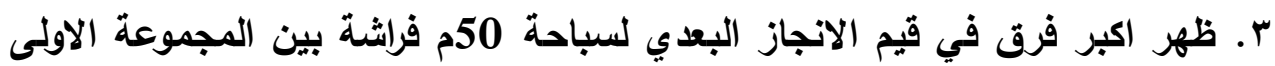

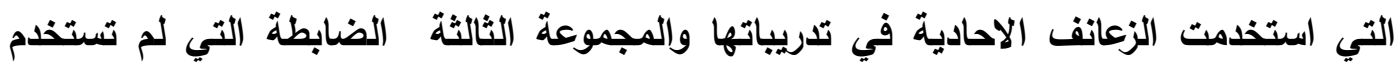
الزعانف او كفوف السباحة في التدريب . ع. ظهر الفرق معنويا" ايضا" بين المجموعة التجريبية الاولى التي استخدمت الزعانف

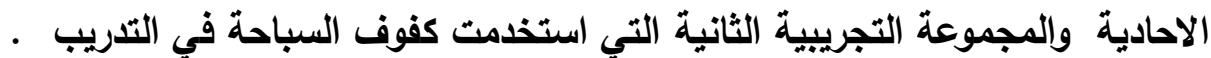

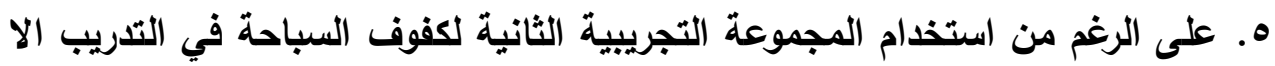
انه لم يكن هناتك فرق معنوي دال احصائيا" بين نتائجها ونتائج المجموعة الثالثة (الضابطة) التي فئي

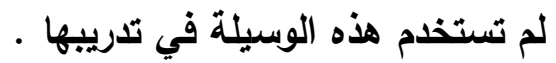
7 ـ تبين من اعلاه ان استخدام زعانف الرجلين الاحادية في التدريب ذات تأثير اكبر في تطوير انجاز سباحة الفراشة من استخدام كفوف السباحة في تدريب الاعمار (13 ـ 14) سنة ـ r-o اعتمادا على الاستنتاجات اعلاه وصى الباحث : 1. ضرورة تركيز المدربين على استخدام الوسائل التدريبية المساعدة ولاسيما زعانف الرجلين الاحادية خلال التدريب المائي لسباحي الفراشة . r. اجراء بحوث ودراسات اخرى لاستخدام الزعانف المنفردة والاحادية في تطوير انجاز انواع اخرى من السباحة (الحرة والصدر والظهر) للمسافات القصيرة ولفئات عمرية مختلفة .

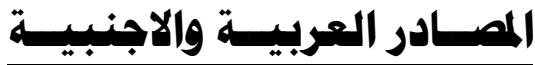

ه احمد عبد الفتاح ابو العلا ـ بيولوحيا الرياضة ـ القاهزة : دار الفكر للطباعة ، 1981. ه اسامة كامل راتب وعلي محمد زكي الاسس العلمبة للسباحة .تدريب ـ تخطيط ـ برامج ـ تحليل حركي . القاهرة : دار الفكر العربي ، 1998 ـ 


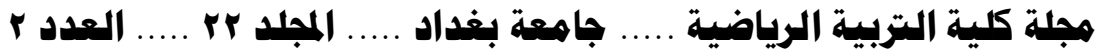

> عبد الرحمن عدس وخليل يوسف .الاحصاء للباحث في التربية والعلوم الانسانية ـ عمان : دار الفكر للنشر والتوزيع ، 1988 ( 198

علي مروش .السباحة ـ الجزائر : دار الهاى للطباعة والنشر والتوزيع ، 1990

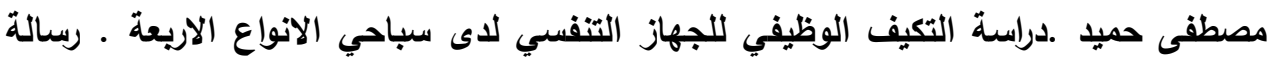
ماجستير ، كلية التربية الرياضية ،جامعة بغداد ، 1996 م 196

Costill , DL .Maglischo EW , Richardson AB :Swimming .Blachwell Scientific. London .1992.

Counsilman .E.James:The Science of Swimming . Prentice. Hall , Inc. 1968.

Fina - Hand book . 1994,1996, Sw .(9) .

Maglisho, E.W. : Swimming Faster, Mayfield Publishing Co. Ltd., California State University , 1982.

Martin, Collis and Bill Kirchhoff, Swimming, Allyh and Bacon, Inc. Bosto 